\title{
Recuerdo de Bruno Bettelheim
}

Contemporáneo estricto de un ensayista y pensador tan rico como Elias Canetti, el destacado psicólogo y analista cultural Bruno Bettelheim nació en Viena en 1903, y ha sido testigo fundamental de un momento de gran esplendor en la ciencia y literatura centroeuropeas. De antemano, fue un notable estudioso de temas estéticos, disciplina en la que se doctoró, antes de ser instruido en el psicoanálisis por un discípulo de Sigmund Freud. Su experiencia psicológica y vital se vio interrumpida por los desastres políticos del siglo XX. Tras la anexión austriaca, Bettelheim fue recluido durante un año en los campos de Dachau y Buchenwald, una experiencia sobre la que va a reflexionar de forma excepcional, como Primo Levi o como Jean Améry. Tras su liberación temprana, al ser por fortuna reclamado, redactó un primer escrito importante, en 1943, sobre el comportamiento individual y colectivo en situaciones límite (en Journal of Abnormal and Social Psychology, 38, 1943), aunque su reflexión sobre las técnicas de degradación humana hasta sus extremos más informes se halla en otros libros como $E l$ corazón bien informado (1960; FCE, 1973); Sobrevivir, el holocausto una generación después (1952, Crítica, 1982). Se quitó la vida, ya anciano, en Los Ấngeles en 1990, como lo hicieron esos otros dos deportados.

Bettelheim logró emigrar a los Estados Unidos pronto. Allí inició una carrera distinta, independiente en parte de la anterior. Se dedicó durante unos treinta años al tratamiento de enfermedades mentales de la niñez, en la Escuela Ortogénica Sonia Shankman, dependiente de la Universidad de Chicago, de la que fue profesor. Él reorganizó totalmente en 1944 esa escuela dedicada al mundo infantil gravemente perturbado; $y$, de hecho, la dirigió hasta su jubilación, en 1973. Bettelheim -que también ha estudiado el mundo infantil en los kibbutz de Israel-, realizó una labor pionera en el tratamiento de los niños autistas, de esos seres «incapaces de interacción con el mundo» que renuncian a hablar y permanecen aislados de todo contacto afectivo con el exterior, encerrados en un universo secreto. Hasta ser conocidas sus investigaciones se les consideraba incurables, pero él logró devolver a muchos de ellos a la vida ordinaria, poniendo en marcha un pensamiento optimista, atento a lo particular, paciente, respetuoso, como lo demuestra su libro más conocido La fortaleza vacía. El autismo infantil y el nacimiento del yo (1967; Paidós, 2001). Véase también, entre otros, Con el amor no basta (1950; Hogar del libro, 1983), Fugitivos de la vida (1955; Crítica, 1975).

Ha escrito además un texto polémico, invirtiendo (o completando o perturbando) el concepto freudiano de envidia del pene: Heridas simbólicas. Los ritos de pubertad y el macho envidioso (1954; Barral, 1974). En muy diversos trabajos suyos prevalece una interpretación a la vez original en sus argumentos y clásica en el fondo dentro del primer psicoanálisis: Diálogos con las madres de niños normales (Barral, 1973). Lo mismo sucede en un libro sobre la importancia de los 
relatos clásicos, más o menos provenientes del folklore, Psicoanálisis de los cuentos de hadas (1975; Crítica, 2005), que va desde la Biblia y las Mil y una noches hasta, especialmente, las narraciones de los hermanos Grimm. Pero nunca estuvo ausente el mundo cultural de su juventud, pues cinco años antes de su muerte, en 1985, escribió «La Viena de Freud» para la exposición parisina Vienne, l'apocalypse joyeuse, 1880-1938, que se recogió entre los importantes artículos recopilados al final de su vida: El peso de una vida (1989; Crítica, 1991).

No hace mucho se ha celebrado el centenario de su nacimiento. Por ello, recuperamos un retazo de su memoria con esta entrevista, realizada un año después de dejar su trabajo clínico, y por tanto una vez cerrada su experiencia central en el campo psiquiátrico.

¿Tiene alguna idea sobre cómo evitar que haya tantas enfermedades mentales?

Sería necesario que los padres y los profesores se decidieran a sacar provecho de las enseñanzas del psicoanálisis, y ¡hasta ahora no lo han hecho! Toda la educación del inconsciente está aún por inventar. Pero sólo puede lograrse acumulando experiencias...

¿Cómo pasó usted del psicoanálisis, su formación inicial, a la idea de un medio terapéutico como el que creó en la escuela ortogénica?

Un poco por casualidad. En Viena, donde vivíamos antes de la guerra, habían llevado a Anna Freud una niña que parecía demasiado enferma como para ser sometida con provecho a un tratamiento analítico clásico. Cabía, sin embargo, alguna esperanza si se conseguía que pasase las veinticuatro horas del día en un ambiente en el que incluso los gestos más cotidianos estuviesen perfectamente calculados sobre la base de las enseñanzas del psicoanálisis. Con el consentimiento de mi mujer, propuse acogerla en mi casa, se quedó con nosotros siete años y realizó progresos que superaron todo lo previsto. Al mismo tiempo me convencí de la eficacia de un ambiente terapéutico total y de la imposibilidad de exigir semejante esfuerzo a una familia media.

También influyó mi experiencia en los campos de concentración: estuve preso durante un año en Dachau; luego, en Buchenwald. Al ver hasta qué punto semejante entorno podía transformar la personalidad de los prisioneros, comencé a pensar en lo contrario, a decirme a mí mismo que un medio ambiente totalmente favorable debía probablemente suscitar modificaciones tan profundas como esas, pero positivas.

Los niños que acoge la escuela ortogénica han sido enviados en su mayoría por médicos que los juzgaban incurables. Según parece, el ochenta y cinco por ciento salen de su institución curados; o, con palabras de Freud, "con capacidad para amar y para trabajar». ¿Cómo explica ese éxito? 
Por el medio terapéutico total que hemos creado. Los psicóticos, sean niños o adultos, confían no en lo que les decimos sino en lo que comprueban por su propia experiencia. El primer mensaje que captan al entrar en un hospital psiquiátrico tradicional es: «Tienes que cambiar» y «La persona importante aquí no eres tú, si no yo o nosotros que nos hacemos cargo de ti». Los edificios más imponentes, mejor decorados, están reservados para la administración o para la recepción de visitantes. La distribución de los locales y el reglamento interno están concebidos para comodidad del personal, no para la de los enfermos. Además, a éstos se los alberga, $\mathrm{o}$, mejor dicho, se los encierra en dormitorios en los que la gente normal se negaría a vivir. Además, no se les encarga nada que pudiera mantenerlos ocupados.

¿Qué conclusiones pueden extraer de todo ello? Nuestro enfoque es radicalmente diferente. Tratamos de hacer comprender al enfermo que no le pedimos nada en absoluto, que sólo deseamos que su estancia entre nosotros sea lo más confortable posible. Los niños están distribuidos por grupos de seis en los dormitorios, en los que ellos mismos han elegido las cortinas, el color de las paredes. Cada uno tiene un rincón personal, que nadie toca. Las duchas son amplias y cómodas: los baños son un pretexto para volver a descubrir los placeres del cuerpo; no tienen una función de limpieza, pues ello equivaldría a decir que se está «sucio». El comedor es acogedor, y las salas de estar, numerosas; hay un gran terreno de juegos, y obras de arte en todas partes. Una gigantesca estatua de mujer acostada, que llamamos «la señora», ha permitido a más de uno de nuestros niños explorar, sin demasiados riesgos, sus relaciones con la madre, golpean o acarician la estatua, se refugian en su regazo...

Este decorado no basta para explicar su éxito, sino que traduce cierta actitud.

Los niños permanecen con nosotros tanto tiempo cuanto sea preciso: un promedio de tres a seis años, pero a veces muchos más... Es un trabajo muy largo, a menudo penoso, el de reconstruir su personalidad. La mayoría de los hospitales psiquiátricos tienen prisa porque sus enfermos salgan. Nosotros, no. Apurar a alguien es darle la impresión de que se le trata con ligereza. Nuestro objetivo es, antes al contrario, devolverles a los niños que nos confían el sentimiento de su propia valía.

Además, respetamos sus síntomas, sean cuales fueren. Constituyen lo más importante, lo más precioso que el enfermo mental ha construido, dado que eso es lo que le ha permitido defenderse, sobrevivir. Reconocer el valor de un síntoma es un primer paso hacia su comprensión y su cura. Recuerdo un niño pequeño -llamémosle John-, que llegó a nosotros prácticamente mudo, totalmente replegado sobre sí mismo, incapaz de aprender nada en clase. Sus padres pensaban que era 
un simple espíritu. Después de cinco años a nuestro lado, empezó a hacer progresos, muy lentos: aprendía a leer algunas palabras, que olvidaba de inmediato. Nos contaba una serie de sueños en los que caminaba por una carretera, que de pronto encontraba cortada por un muro infranqueable.

Sentía, sin saber por qué, que le era esencial ir más lejos. Comenzó entonces por apartarse del camino central para bordear el muro, pero, cuando trataba de continuar, surgía un nuevo muro, que avanzaba hacia él y amenazaba con aplastarlo contra el primero. Se despertaba dando gritos de terror. Luego trató de trepar el muro: al llegar arriba, perdía el equilibrio, y por poco se estrellaba al caer. Durante todo ese tiempo continuaba aprendiendo a leer algunas palabras, que olvidaba rápidamente. Luego llegó una segunda etapa, con progresos más evidentes: el contenido del sueño había variado. Ahora John bordeaba el muro, pero antes de continuar su camino se volvía para destruirlo, piedra a piedra. Cuando estaba despierto, comenzaba a salir del aislamiento afectivo, pero aún tenía mucho camino que recorrer. Luego, el sueño experimentó una tercera variación: con su montón de piedras, John se construyó una casa. Meses más tarde, estaba curado.

Actualmente, «el simple de espíritu» es profesor de Universidad. Para salir adelante, tuvo que reconocer el valor de su «muro», de sus bloqueos, aprenderlo a utilizar, de manera constructiva. Bordearlo, franquearlo, limitarse a borrarlo no servía de nada; equivalía a dejarlo sin protección.

Ese respeto absoluto por los síntomas debe ser difícil, a veces, para el equipo de educadores y profesores. Usted cita a una educadora a la que mordió un niño; y que estaba tan preocupada por los problemas de éste que exclamó: « ¿Cuidado, te harás daño en los dientes!». El niño soltó la presa de inmediato... eso sí, ;había que tenerlo en la cabeza!

El trabajo escolar es duro, pero aporta muchas satisfacciones: es esencialmente creador, casi una obra de arte. La mayoría de los hospitales psiquiátricos encierran a los enfermeros y a los que se ocupan de las curas, es decir, a aquellos que están más directamente en contacto con los enfermos en una red de normas y prohibiciones que los paralizan. En la escuela ortogénica no existen reglas; la seguridad y el bienestar de los niños está antes que nada.

El trabajo es también muy formador: nuestros educadores, aprenden tanto sobre sí mismos como sobre los niños que atienden. Es imposible comprender a un enfermo mental si no se comienza por comprenderse a uno mismo. Una de nuestras enfermeras se había dejado golpear por un niño durante mucho más tiempo de lo que justificaba la crisis. Al preguntarse por qué, se dio cuenta de que, inconscientemente, trataba de someterse a ciertos castigos porque en su acceso de celos, olvidado hacía mucho tiempo, había perseguido a su hermana con un cuchillo de cocina... 
Se le ha reprochado mucho la aplastante responsabilidad que atribuye a los padres en la aparición del autismo infantil.

Mis principales detractores son precisamente los padres de niños autistas incapaces de reconocer su propia responsabilidad. Es mucho más fácil afirmar: «Es genético, es la fatalidad». Por supuesto que esos niños son particularmente sensibles. Reinterpretan como una amenaza cada gesto de sus padres, por los que se sienten rechazados, y optan por refugiarse en un aislamiento total. Un niño menos sensible, en las mismas circunstancias, quizá se habría convertido simplemente en un neurótico, un delincuente o un rebelde. Pero es ésta una disputa en la que no quiero enzarzarme. Lo importante es ayudar a los niños. Los partidarios de la teoría genética son incapaces de hacerlo.

Proponen algunos un sistema de reeducación que permita aprender los rudimentos del lenguaje, los gestos más útiles para la vida cotidiana.

He visto niños sometidos a ese tratamiento. Parecían cambiar, pero lo hacían sólo provisionalmente. Cuando he vuelto a verlos, su comportamiento era más autista que nunca.

La escuela ortogénica sólo puede acoger a cincuenta niños. Es un número escaso. Y resulta caro, pues se quedan mucho tiempo.

La escuela depende de un organismo investigador. Su papel es dar un ejemplo, mostrar lo que se puede hacer. Es la sociedad la que debe luego seguir el movimiento o hacerse cargo de sus responsabilidades. No podemos preocuparnos por ese problema, ya que si no sería imposible realizar nuestro trabajo. En cuanto al coste de la estancia entre nosotros, es de ocho mil dólares por niño y por año. Menos que un hospital psiquiátrico normal. Los dos tercios de los niños provienen de familias bastante acomodadas, que pueden pagar la totalidad o parte del tratamiento. Los demás quedan a cargo de los poderes públicos.

Usted dejó la Escuela Ortogénica el año pasado [en 1973], después de haberla dirigido durante treinta años.

Tengo setenta y dos años. A mi edad, uno se fatiga enseguida, lo cual resulta incompatible con un trabajo que exige tamaña disponibilidad mental y afectiva... Preferí cerrar con calma la transición de mi puesto, y hacerlo en una época en la que aún podía formar a mi sucesor y presentarlo a los niños. 